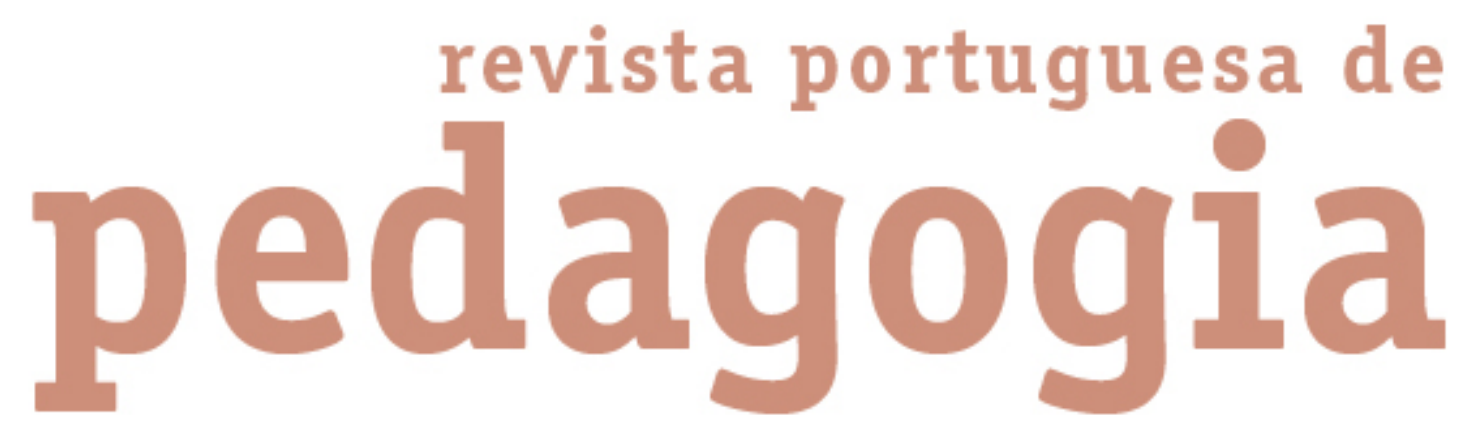

\title{
Perceção da transferência das aprendizagens em educação e formação de adultos: um estudo num centro de emprego e formação profissional
}
Autor(es):
Lopes, Letícia Raquel Gonçalves; Bidarra, Maria da Graça Amaro;
Barreira, Carlos Manuel Folgado

Publicado por: Imprensa da Universidade de Coimbra

URL

persistente:

URI:http://hdl.handle.net/10316.2/40691

DOI:

DOI:https://doi.org/10.14195/1647-8614_50-1_5

Accessed : $\quad$ 26-Apr-2023 14:33:50

A navegação consulta e descarregamento dos títulos inseridos nas Bibliotecas Digitais UC Digitalis, UC Pombalina e UC Impactum, pressupõem a aceitação plena e sem reservas dos Termos e Condições de Uso destas Bibliotecas Digitais, disponíveis em https://digitalis.uc.pt/pt-pt/termos.

Conforme exposto nos referidos Termos e Condições de Uso, o descarregamento de títulos de acesso restrito requer uma licença válida de autorização devendo o utilizador aceder ao(s) documento(s) a partir de um endereço de IP da instituição detentora da supramencionada licença.

Ao utilizador é apenas permitido o descarregamento para uso pessoal, pelo que o emprego do(s) título(s) descarregado(s) para outro fim, designadamente comercial, carece de autorização do respetivo autor ou editor da obra.

Na medida em que todas as obras da UC Digitalis se encontram protegidas pelo Código do Direito de Autor e Direitos Conexos e demais legislação aplicável, toda a cópia, parcial ou total, deste documento, nos casos em que é legalmente admitida, deverá conter ou fazer-se acompanhar por este aviso. 


\section{revista portuguesa de pedagogia}

EDUCAÇÃO E FORMAÇÃO DE ADULTOS 


\title{
Perceção da Transferência das Aprendizagens em Educação e Formação de Adultos: Um Estudo num Centro de Emprego e Formação Profissional
}

\author{
Letícia Raquel Gonçalves Lopes', Maria da Graça Amaro Bidarra² e Carlos \\ Manuel Folgado Barreira ${ }^{3}$
}

\begin{abstract}
Resumo
O presente artigo pretende ser um contributo para o estudo da perceção da transferência das aprendizagens em educação e formação de adultos, tendo como base o modelo de Holton e colaboradores (Holton, Bates, \& Ruona, 2000), retomado por Caetano (2007), e na metodologia que lhe está associada, envolvendo deste modo a adaptação do Learning Transfer System Inventory (LTSI), na versão portuguesa de Velada (2007). Participaram no estudo 190 formandos, integrados em cursos de Educação e Formação de Adultos num Centro de Emprego e Formação Profissional, de diferentes áreas de formação, com diferentes habilitações e equivalências escolares e com idades compreendidas entre os 21 e 50 anos. Os resultados obtidos indicam uma positiva perceção da transferência, em termos globais, revelando-se diferenças significativas quanto ao sexo, às habilitações académicas, ao motivo da frequência da formação, à satisfação com a formação e ao grau de confiança na aquisição de um trabalho em consequência da formação.
\end{abstract}

Palavras-chave: formação profissional; Educação e Formação de Adultos; transferência de aprendizagens

1 Centro de Emprego e Formação Profissional de Águeda. Email: leticiasocial@gmail.com

2 Professora Associada da Faculdade de Psicologia e de Ciências da Educação da Universidade de Coimbra. Email: gbidarra@fpce.uc.pt

3 Professor Auxiliar da Faculdade de Psicologia e de Ciências da Educação da Universidade de Coimbra. Email: cabarreira@fpce.uc.pt 


\title{
Perception of Learning Transfer in Adult Education and Training: A study in an Employment and Professional Training Centre
}

\begin{abstract}
The present paper intends to make a contribution to the study of perceptions of learning transfer in adult education and training. It was based on Holton and his collaborators' Model (Holton, Bates, \& Ruona, 2000), taken up by Caetano (2007), and on the methodology associated with it, including the adaptation of the Learning Transfer System Inventory (LTSI) in the Portuguese version by Velada (2007). A total of 190 trainees from different vocational areas participated in this study. All participants were enrolled in Adult Education and Training programmes in an Employment and Professional Training Centre. The age range of the participants was between 21 and 50 years old and they had different levels of education. The results of the study show, in general, a positive perception of knowledge transfer. Significant differences were observed with regard to sex, levels of education, reason for attending a vocational course, satisfaction with the training provided, and level of confidence in finding a job after the training course.

Keywords: vocational training; Adult Education and Training; learning transfer

\section{Percepción de la Transferencia de los Aprendizajes en Educación y Formación de Adultos: Un Estudio en el Centro de Empleo y Formación Profesional}

\section{Resumen}

El presente artículo pretende contribuir al estudio de la percepción de la transferencia de los aprendizajes en educación y formación de adultos, con base en el modelo de Holton y colaboradores (Holton, Bates \& Ruona, 2000), retomado por Caetano (2007), y en la metodología asociada, envolviendo de este modo la adaptación del Learning Transfer System Inventory (LTSI) en la versión portuguesa de Velada (2007). En el estudio participaron 190 personas, inscritas en cursos de Educación y Formación de Adultos en el Centro de Empleo y Formación Profesional, pertenecientes a diversas áreas de formación, con diferentes grados de escolaridad y equivalencias académicas y con edades comprendidas entre los 21 y 50 años. En términos generales, los resultados obtenidos indican una percepción positiva de la transferencia; además, se evidencian diferencias significativas en cuanto al sexo, los niveles de escolaridad, el motivo de la participación en la formación, la satisfacción con la formación y el grado de confianza en la consecución de un trabajo gracias a la formación.

Palabras clave: formación profesional, Educación y Formación de Adultos, transferencia de aprendizajes 


\section{Introdução}

As organizações têm vindo a integrar de forma positiva a formação de adultos, acreditando que esta é um contributo válido para o desenvolvimento individual, profissional e organizacional. Concomitantemente, o conceito relativamente recente de Aprendizagem ao Longo da Vida prevê a necessidade de adaptação, de inovação e de atualização de competências. A própria filosofia das relações laborais, pautadas, algumas vezes, por um cariz de insegurança, de competitividade e de mobilidade, exige que o indivíduo seja flexível, adaptável e que as suas competências estejam atualizadas. Exige-se do indivíduo o mesmo que se espera da formação: que apresente resultados imediatos (Caetano, 2007).

A formação surge como uma solução às problemáticas individuais e coletivas, assumindo-se como uma resposta funcional face às alterações céleres de um contexto global, caracterizado por uma conjuntura social e económica problemática (Canário, 2007), pois cada vez mais as organizações esperam novas aptidões dos seus colaboradores e exigem novos níveis de saber, quer ao nível do domínio cognitivo, quer do domínio psicomotor, quer ainda do domínio socioafetivo (Inácio, 2007). A aprendizagem ao longo da vida relaciona-se com a necessidade de formação adequada, tendo em atenção alguns aspetos determinantes, nomeadamente que se trata de um público de aprendentes adultos que pretendem uma aquisição de conhecimentos que possam implementar rapidamente no seu contexto, seja ele familiar, social ou profissional.

No entanto, a frequência da formação não garante por si só uma melhoria no desenvolvimento e na prestação profissional e organizacional e conclui-se que o investimento pode ser inglório pela incapacidade de implementar as aprendizagens num contexto real. Holton, Bates e Ruona (2000) também sugerem que o investimento em formação atinge grandes proporções em termos económicos, mas que as empresas não podem restringir-se a exigir os resultados do seu investimento sem ter em atenção determinados fatores, existindo uma certa escassez ou mesmo ausência de estudos sobre a transferência de aprendizagens. Caetano (2007) reforça esta ideia afirmando que "a análise dos efeitos reais da formação tem sido relativamente escassa e não permite sustentar linearmente a crença referida de que a formação melhora efectivamente o desempenho" (p. 20).

De clarificar que na corrida à formação e no desejo ávido dos seus benefícios, que se querem imediatos, o tecido empresarial esqueceu-se da necessidade de avaliar a intenção formativa, o processo formativo, os colaboradores e o seu papel no resultado da formação, passando a focar as atenções na avaliação da formação quando começam a exigir-se resultados que demonstrem a relevância e a utilidade da mesma (Caetano, 2007). A importância da avaliação surge também 
por pressão da própria sociedade civil que questiona a eficácia dos serviços de educação e que, em certa medida, obriga os decisores políticos a questionarem essa eficiência (Fernandes, 2006).

A avaliação, quer da formação, quer da transferência de aprendizagens, assume-se assim fundamental tendo em consideração os custos associados e os resultados esperados, que nas últimas décadas não têm sido proporcionalmente diretos (Caetano, 2007). O conceito de transferência suscita pois largo interesse tanto para os indivíduos como para as organizações, pois ambos investem tempo e dinheiro em atividades formativas, assumindo grande importância na educação e formação de adultos, estendendo-se igualmente à formação de professores (Lázaro, 2012).

$\mathrm{Na}$ tentativa de desenvolver o conceito de transferência, Baldwin e Ford (1988), Burke e Hutchins ( 2007), Caetano (2007), e Devos, Dumay, Bonami, Bates e Holton (2007) referem que uma transferência efetiva se caracteriza pela aplicabilidade dos conhecimentos, das competências e dos comportamentos adquiridos durante a formação para um contexto de trabalho durante um determinado tempo. Caetano (2007) acrescenta ainda que a transferência de conhecimentos espelha as alterações comportamentais adquiridas durante e em consequência da formação. É de salientar que os autores acima citados sublinham que para haver transferência de aprendizagens é fundamental que durante o processo de formação os formandos adquiram competências sobre como transferir os conhecimentos aprendidos para um contexto real de trabalho. Miranda e Bahia (2005), reportando-se ao contexto escolar, reforçam esta posição esclarecendo que a transferência não é de todo um processo espontâneo e que é necessário ensinar os alunos a transferir. Cabe ao professor utilizar métodos adequados e implementar na sua sala de aula um ambiente reflexivo e atividades que permitam ao aluno adquirir, desenvolver e treinar competências de transferibilidade, capacitando-o a que, de uma forma flexível, consiga encontrar soluções para novos problemas. Existem mesmo variáveis que podem potenciar o processo de transferência efetiva das aprendizagens adquiridas associadas aos sujeitos, às tarefas a desenvolver e às situações de aprendizagem. Cabe ainda referir que existem vários tipos de transferência, bem como diferentes teorias explicativas deste processo, que se revela bastante complexo (Miranda \& Bahia 2005), dado que integra em si um conjunto significativo de variáveis que devem ser consideradas (Barreira, 2009).

Baldwin e Ford (1988) também defendem a existência de um conjunto de fatores que estão envolvidos na transferência de aprendizagens, nomeadamente a motivação, fatores de personalidade e características do ambiente de trabalho, incluindo supervisão e suporte dos pares. Da mesma forma, Holton, Bates e Ruona (2000) reiteram 
a existência de um conjunto de fatores que influenciam diretamente o processo de transferência, considerando ser necessário estudar os fatores que inibem a transferência dos conhecimentos, sugerindo um conjunto de escalas de transferência que permitirão estabelecer correlações e resultados significativos e válidos.

Perante a dificuldade de avaliar a transferência e tentando estabelecer a ponte entre os quadros teóricos e a necessidade de avaliação efetiva no local de trabalho, Holton e colaboradores criaram um sistema de avaliação que foi sendo melhorado e consolidado ao longo do tempo (Holton, Bates \& Ruona, 2000).

Na perspectiva de Caetano (2007), o modelo de Holton baseia-se em três condições fulcrais: design ou estruturação da formação, características dos formandos e ambiente de trabalho, traduzíveis também em estruturação da ação, em características individuais e coletivas e em ambiente e apoio organizacional dado aos formandos. Em 1996/1997, Holton inicia então a conceção de um instrumento de avaliação, o Learning Transfer System Inventory (LTSI), à altura ainda designado por Learning Transfer Questionnaire, com escala de resposta de tipo Likert que permitiria verificar o nível de influência destas condições na transferência das aprendizagens para um contexto prático de trabalho (Holton, Bates, Seyler, \& Carvalho, 1997).

Refletindo sobre o modelo de Holton, podemos considerar que nele confluem os modelos de avaliação de Stufflebeam e de Kirkpatrick, pois articula a análise sistematizada do processo avaliativo com o objetivo definido de centrar também a sua atenção nos resultados, que, por sua vez, se pretendem positivos quer a nível individual, quer a nível organizacional, quer ainda num patamar económico (Holton, Bates, \& Ruona 2000). O LTSI, conforme o conhecemos, é o resultado de um conjunto de estudos e experiências realizadas por Holton e colaboradores, de forma a torná-lo num instrumento fiável de avaliação dos fatores que influenciam a transferência dos conhecimentos adquiridos na formação para um contexto laboral. Velada (2007) traça todo um percurso evolutivo do LTSI e da contextualização teórica que lhe está associada até o apresentar nos moldes atuais, procedendo à sua adaptação num estudo realizado com 218 participantes maioritariamente com habilitações acima do $12 \circ$ ano de escolaridade (44.5\%), que frequentavam diversas ações de formação em dois Centros de Formação de Lisboa.

É neste enquadramento que desenvolvemos o estudo empírico, que a seguir se apresenta, que decorreu num Centro de Emprego e Formação Profissional da zona centro de Portugal continental, que teve como principal objetivo analisar a perceção que os formandos têm da transferência das suas aprendizagens, em função de variáveis sociodemográficas. Para o efeito procedeu-se à adaptação da versão portuguesa do 
LTSI (Velada, 2007) de modo a torná-lo adequado ao estudo em causa, que envolve participantes que apenas possuem o 6ำ e 9ำ ano de escolaridade (Lopes, 2014).

\section{Metodologia}

\section{Medidas e Procedimentos}

$\mathrm{Na}$ avaliação da perceção da transferência das aprendizagens utilizámos, como já foi referido, a metodologia proposta por Holton. O Learning Transfer System Inventory é constituído por três escalas, que, por sua vez, integram 16 subescalas, que se relacionam com as condições que podem facilitar ou perturbar o processo de transferência (cf. Quadro 1).

\section{Quadro 1}

Escalas e as Subescalas do LTSI e Índices de Consistência Interna (adaptado de Velada, 2007)

\begin{tabular}{|c|c|c|c|}
\hline Escalas & \multicolumn{2}{|r|}{ Subescalas } & $\begin{array}{c}\text { Alfa de Cronbach } \\
\text { Consistência Interna }(\alpha)\end{array}$ \\
\hline Conceção da & - & Capacidade Pessoal para Transferir; & .68 \\
\hline \multirow[t]{3}{*}{ Formação } & - & Perceção de Validade de Conteúdo; & .84 \\
\hline & - & Design de Transferência; & .85 \\
\hline & - & Oportunidade para utilizar a Formação. & .70 \\
\hline \multirow[t]{5}{*}{ Fatores Individuais } & - & Preparação Prévia dos Formandos; & .73 \\
\hline & - & Motivação para Transferir; & .83 \\
\hline & - & Esforço de Transferência - Expetativas de & .81 \\
\hline & & Desempenho; & \\
\hline & - & Autoeficácia de Desempenho. & .76 \\
\hline Fatores & - & Resultados Pessoais Positivos; & .69 \\
\hline \multirow[t]{7}{*}{ Organizacionais } & • & Resultados Pessoais Negativos; & .76 \\
\hline & • & Suporte dos Pares; & .83 \\
\hline & • & Suporte do Supervisor; & .91 \\
\hline & • & Sanções do Supervisor; & .63 \\
\hline & • & Desempenho - Expetativas de Resultados; & .83 \\
\hline & • & Resistência/Abertura à Mudança; & .85 \\
\hline & $\cdot$ & Feedback de Desempenho. & .70 \\
\hline
\end{tabular}

A primeira escala denominada Conceção da Formação é reconhecida na literatura por diversos autores, nomeadamente Stufflebeam e Shinkfield (1993), e assume-se 
como um contributo imprescindível para o sucesso de uma ação de formação, uma vez que a planificação, definição de objetivos e implementação de estratégias pode auxiliar e motivar os formandos a transferirem para o seu contexto de trabalho os conhecimentos adquiridos no contexto formativo. A escala referente aos Fatores Individuais transporta-nos para o facto de cada indivíduo concentrar em si um conjunto de características que o distingue dos demais. Estas especificidades individuais podem ir desde os traços da personalidade até à motivação, passando pelas necessidades sentidas e objetivos a atingir. São estas diferenças que podem influenciar quer positiva, quer negativamente a forma de olhar e de participar na formação. Por último, os Fatores Organizacionais remetem para o ambiente de trabalho que rodeia o indivíduo e que representa uma influência marcante no seu desempenho profissional e na transferência da formação. Segundo Noe e Schmitt (1986), a relação entre motivação e ambiente de trabalho explicam entre $15 \%$ e $20 \%$ da eficácia da formação. Esta escala está relacionada com o entendimento que o indivíduo tem relativamente ao apoio dos pares, do supervisor e da organização em geral. Verifica-se que o suporte destes agentes tem influência no seu contexto profissional e aqueles impulsionam o sujeito a implementar novas formas de conhecimento. Segundo Velada (2007), um bom relacionamento com os pares e supervisor e um bom ambiente de trabalho tornam-se preditores de um clima de transferência positivo. Esquematicamente, escalas e subescalas organizar-se-iam como indica o Quadro 1.

Seguindo especificamente a operacionalização do conceito de transferência, através das escalas de Holton, adaptadas por Velada (2007), considerámos necessário adequar a terminologia do questionário em termos de vocabulário e proceder à supressão de alguns itens com o objetivo de não dispersar a atenção dos indivíduos, evitando a saturação e as consequentes respostas automatizadas às questões, atendendo igualmente quer à sua baixa escolaridade, quer ao seu afastamento, nalguns casos por muitos anos, de qualquer atividade formativa. Uma vez que estávamos a avaliar a perceção da transferência, adaptou-se a aplicabilidade dos conhecimentos a transferir para um futuro posto de trabalho e para a aplicação das aprendizagens na componente prática do curso. A figura e função de supervisor foram então substituídas pela figura do formador, uma vez que é este que, em contexto de formação, ensina, exemplifica, supervisiona e avalia o desempenho do formando.

Deve salientar-se que os nossos participantes não tinham ainda integrado um posto de trabalho e encontravam-se em pleno percurso formativo, pelo que não foi possível avaliar uma transferência de conhecimentos no local de trabalho. Porém, ainda que em período formativo, considerou-se pertinente estudar a perceção que os formandos tinham da transferência das suas aprendizagens, não para um 
local de trabalho efetivo, uma vez que estavam em situação de desemprego, mas na componente prática que a formação profissional e os cursos de educação e formação de adultos integravam.

O questionário que utilizámos integrou duas partes: A primeira relativa à caracterização sociodemográfica, com 11 questões, e a segunda com 32 itens que permitiram recolher dados sobre a perceção da transferência de aprendizagens.

Na recolha dos dados de identificação sociodemográfica dos participantes, utilizámos as questões que nos pareceram abordar de forma mais pertinente as características individuais dos formandos com o objetivo de estabelecer uma relação estatística com a perceção da transferência das aprendizagens obtida através do LTSI. Considerámos, deste modo, o sexo, a idade, as habilitações escolares, a ação de formação que frequentavam e o respetivo nível de escolaridade, o número de ações de formação que já tinham frequentado na mesma entidade, o motivo da frequência da atual formação, a situação face ao emprego e o tipo de apoio social em que se enquadravam, assim como o grau de satisfação com a formação e a expectativa de integração num posto de trabalho devido à frequência da formação. Estas variáveis pareceram-nos determinantes para a análise da perceção da transferência de aprendizagens.

Relativamente à perceção da transferência das aprendizagens, o questionário original conta com 89 itens. Para o nosso estudo reduzimos o número de indicadores mantendo apenas 32 itens. Os critérios utilizados na supressão de itens passaram primeiramente pela eliminação dos que se revelavam menos adequados ao contexto do estudo em causa, como por exemplo se as chefias se opunham à utilização de novas técnicas aprendidas na formação ou sobre limitações orçamentais da entidade empregadora e secundariamente dos itens que eram redundantes no seu conteúdo, alterando apenas a forma da questão. Foram assim eliminados os itens referentes sobretudo aos fatores organizacionais e às subescalas suporte e sanções do supervisor como por exemplo: $O$ meu supervisor diz-me se estou a fazer um bom trabalho quando utilizo o que aprendi nesta formação; O meu supervisor mostra interesse relativamente ao que aprendi na formação; $O$ meu supervisor considera que esta formação não ajudará o meu trabalho e O meu supervisor não irá gostar do meu trabalho se eu aplicar o que aprendi nesta formação.

Esta redução de itens teve como base potenciais dificuldades de leitura e interpretação, falta de concentração por períodos relativamente longos de tempo que os sujeitos revelam ao realizar atividades similares, a prevenção de situações de possíveis respostas ao acaso pela extensão do questionário original e uma maior adequação à realidade da formação profissional.

Deve referir-se que respeitámos as escalas originais do LTSI - Conceção da Formação, Fatores Individuais e Fatores Organizacionais. Não conseguimos porém 
integrar na análise do nosso estudo as 16 subescalas, conforme o original, devido ao reduzido número de itens em causa e à sua não representatividade na respetiva subescala. As respostas ao questionário, à semelhança do LTSI original, foram dadas numa escala de Likert, variando entre 1 e 5, significando o 1 "Discordo completamente", o 2 "Discordo", o 3 "Não Concordo nem Discordo", 4 "Concordo" e o 5 "Concordo Completamente".

\section{Participantes}

Participaram no estudo 190 formandos, pertencentes a 14 turmas, $67.4 \%$ do sexo feminino e $32.6 \%$ do sexo masculino. Ao grupo etário dos 31 aos 40 anos pertencem $40.5 \%$ dos participantes, seguidos de $27.4 \%$ que têm idades compreendidas entre 41 e 50 anos e de $24.2 \%$ cujas idades se situam entre 21 e 30 anos. Quanto às habilitações escolares, $66.3 \%$ dos participantes tinham o 60 ano de escolaridade e os restantes (33.7\%) tinham ○ 9a ano. A maioria dos participantes (66.3\%) frequentou ações correspondentes ao nível B-3 (9ano) e os restantes 33.7\% frequentaram ações de nível de ensino secundário.

As ações de formação mais frequentadas foram as de Pastelaria (10.0\%), Cuidados e Estética do Cabelo (9.5\%), seguidas de Cozinha, Soldadura e Técnicos/as de Manutenção Industrial cada uma delas com 7.9\%. Por outro lado, as ações menos representadas na amostra foram Serralharia Mecânica I (3.2\%), Cozinha e Pastelaria, Jardinagem e Serralharia Mecânica II, com 5.8\%, e Técnicos/os Auxiliares de Saúde, com $6.8 \%$. Relativamente ao número de ações de formação que os inquiridos frequentaram anteriormente, 55.3\% afirmaram que não tinham frequentado nenhuma, seguidos de $32.6 \%$ que já tinham frequentado uma ação de formação.

Questionados acerca do motivo que os levou a frequentar a formação, 58.9\% dos participantes afirmaram que o fizeram por interesse próprio, seguidos de $26.8 \%$ que indicaram frequentar a formação por imposição e de $12.1 \%$ que o fizeram por sugestão de alguém. Acrescenta-se ainda que 55.2\% dos participantes estavam na situação de desemprego há mais de um ano, seguindo-se 39.5\% que também eram desempregados mas há menos de um ano. Quanto ao apoio social, apurámos que a maioria, concretamente $54.7 \%$, beneficiava de subsídios de desemprego, seguidos de $34.7 \%$ que recebiam bolsa de formação.

Relativamente ao grau de satisfação com a formação, 53.7\% dos participantes manifestaram estar satisfeitos, seguidos de $28.4 \%$ que afirmaram estar muito satisfeitos. No que respeita à perspetiva de encontrar trabalho na sequência da formação frequentada, 13,2\% manifestaram muita confiança, $41.6 \%$ manifestaram confiança, seguidos de $23.7 \%$ medianamente confiantes e de $14.7 \%$ que afirmaram estar pouco confiantes. 


\section{Resultados}

\section{Estrutura e características psicométricas das medidas utilizadas}

Com o objetivo de analisar a estrutura da versão adaptada do LTSI por nós utilizada, procedemos a análises fatoriais em componentes principais numa função confirmatória. Assim, ao conjunto de itens que, teoricamente, constituíam as escalas foi aplicada a análise fatorial no sentido de confirmar, ou não, a existência estatística de um único fator. Em simultâneo, procedemos ao estudo da fiabilidade de cada dimensão através da análise da respetiva consistência interna. O método utilizado consistiu na determinação da correlação item-total corrigida, cujos valores podem variar entre -1 e +1 , e do coeficiente alfa de Cronbach, que pode apresentar resultados entre 0 e 1. Para as duas situações, procuramos valores positivos e o mais elevados possível, ou seja, próximos de 1. Quando tal acontece, podemos admitir a homogeneidade do conjunto de itens e, consequentemente, uma boa consistência interna. Estes procedimentos estatísticos são indicados para a maioria das escalas. No que concerne à consistência interna e, de acordo com a maioria dos autores, resultados iguais ou superiores a 70 são reveladores de boa consistência interna, ainda que sejam aceitáveis valores iguais ou superiores a .60 , principalmente quando é reduzido o número de itens envolvidos (Maroco \& Garcia-Marques, 2006). Os resultados que apresentamos no Quadro 2 foram obtidos através do desenvolvimento dos estudos atrás referidos aos oito itens que foram considerados como constituindo a escala Conceção da Formação.

Quadro 2

Resultados dos Estudos da Análise Fatorial e da Consistência Interna para a Escala Conceção da Formação

\begin{tabular}{cccc}
\hline Item & Peso fatorial & $\begin{array}{c}\text { Correlação } \\
\text { item-total }\end{array}$ & $\begin{array}{c}\text { Alfa se o item fosse } \\
\text { eliminado }\end{array}$ \\
\hline 8 & 0.582 & 0.482 & 0.851 \\
15 & 0.774 & 0.672 & 0.829 \\
16 & 0.785 & 0.679 & 0.829 \\
17 & 0.787 & 0.678 & 0.828 \\
18 & 0.817 & 0.724 & 0.827 \\
19 & 0.688 & 0.580 & 0.840 \\
20 & 0.689 & 0.570 & 0.842 \\
21 & 0.553 & 0.451 & 0.858 \\
\hline
\end{tabular}

$\mathrm{KMO}=0.856 ;$ p M 0.001; Variância explicada $=51.174 \% ; \alpha=0.856$

Verificámos um coeficiente Kaiser-Meyer-Olkin (KMO) com valor compreendido entre 0.8 e 0.9 e o teste de esfericidade de Bartlett revelou-se altamente significativo 
( $p$ < 0.001). Segundo Maroco (2007) e Pestana e Gageiro (2005), estes resultados traduzem uma boa adequação da técnica estatística aos dados em estudo. Verificamos, ainda, que os pesos fatoriais são elevados, estando compreendidos entre 0.55 (item 21) e 0.82 (item 18) e que a variância explicada se situou nos $51.17 \%$. O estudo da consistência interna reforça esta perspetiva atendendo a que as correlações item-total são elevadas, com valores compreendidos entre .45 (item 21) e.72 (item 18) e tendo em consideração que o valor de alfa obtido de .86, é revelador de boa consistência interna. Constatou-se, ainda, que a eliminação de qualquer dos itens não faria aumentar o valor do coeficiente e, consequentemente, melhorar a consistência interna da dimensão escala. Estes resultados suportam, em termos estatísticos, a existência de um único fator, ou seja, são concordantes com a perspetiva teórica de que a escala Conceção da Formação era constituída pelos itens 8, 15, 16, 17, 18, 19, 20 e 21.

Para a escala Fatores Individuais observamos uma situação semelhante à descrita para a escala anterior. O valor do coeficiente $\mathrm{KMO}$ situou-se entre 0.8 e 0.9, o teste de esfericidade de Bartlett apresentou resultado altamente significativo $(p<0.001)$ e a percentagem de variância explicada foi de $42.7 \%$. Os pesos fatoriais dos itens apresentaram valores elevados situando-se entre 0.465 (item 1) e 0.781 (item 31). Verificamos, também, que as correlações item-total são todas positivas com valores compreendidos entre .41 (item 1) e .67 (item 31). O valor do coeficiente alfa para o conjunto dos onze itens foi .86 e a eliminação de qualquer dos itens não implicava aumento deste valor. Todos estes resultados constituem a confirmação estatística de que os onze itens que integram a escala em estudo representam um grupo homogéneo e compatível com a perspetiva teórica (cf. Quadro 3).

Quadro 3

Resultados dos Estudos da Análise Fatorial e da Consistência Interna para a Escala Fatores Individuais

\begin{tabular}{cccc}
\hline Item & Peso fatorial & $\begin{array}{c}\text { Correlação } \\
\text { item-total }\end{array}$ & $\begin{array}{c}\text { Alfa se o item fosse } \\
\text { eliminado }\end{array}$ \\
\hline 1 & 0.465 & 0.412 & 0.855 \\
2 & 0.483 & 0.430 & 0.854 \\
3 & 0.634 & 0.549 & 0.844 \\
4 & 0.626 & 0.554 & 0.843 \\
5 & 0.601 & 0.509 & 0.847 \\
22 & 0.714 & 0.616 & 0.840 \\
23 & 0.656 & 0.538 & 0.844 \\
24 & 0.714 & 0.582 & 0.841 \\
29 & 0.717 & 0.602 & 0.841 \\
30 & 0.719 & 0.620 & 0.838 \\
31 & 0.781 & 0.674 & 0.834 \\
\hline
\end{tabular}

$\mathrm{KMO}=0.823 ; \mathrm{p} \mathrm{M} 0.001 ;$ Variância explicada $=42.682 \% ; \alpha=.86$ 
$\mathrm{Na}$ escala relativa aos Fatores Organizacionais foi observado um valor mais baixo para o coeficiente $\mathrm{KMO}$, estando este compreendido entre 0.7 e 0.8 mas, mesmo assim, aceitável e revelador da adequação da técnica estatística aos dados envolvidos. Este facto é suportado pelo resultado altamente significativo observado para o teste de esfericidade de Bartlett $(p<0.001)$. A percentagem de variância explicada foi a mais baixa das três escalas (31.68\%) e três dos itens (7, 14 e 27) apresentaram pesos fatoriais relativamente baixos, respetivamente, 0.286, 0.095 e 0.115 (cf. Quadro 4). Os pesos fatoriais dos restantes itens situaram-se entre 0.368 (item 25) e 0.760 (item 12). Os itens 7, 14 e 27 também apresentaram baixas correlações item-total e se fossem retirados da escala verificar-se-ia um aumento dos valores do coeficiente alfa de Cronbach. No entanto, a sua presença mantém a consistência interna num nível aceitável ( $\alpha=.77$ ) e a informação que seria perdida com a respetiva eliminação era mais penalizadora para o estudo do que a melhoria da consistência interna daí resultante. A ponderação destes dois aspetos levou-nos a optar por manter a escala com todos os itens previstos teoricamente, ou seja, a escala ficou constituída pelos itens $6,7,9,10,11,12,13,14,25,26,27,28$ e 32.

Quadro 4

Resultados dos Estudos da Análise Fatorial e da Consistência Interna para a Escala Fatores Organizacionais

\begin{tabular}{cccc}
\hline 6 & 0.506 & 0.400 & 0.755 \\
\hline 7 & 0.286 & 0.168 & 0.781 \\
9 & 0.705 & 0.578 & 0.738 \\
10 & 0.643 & 0.504 & 0.745 \\
11 & 0.722 & 0.581 & 0.734 \\
12 & 0.760 & 0.647 & 0.732 \\
13 & 0.699 & 0.599 & 0.738 \\
14 & 0.095 & 0.074 & 0.789 \\
25 & 0.368 & 0.247 & 0.768 \\
26 & 0.610 & 0.525 & 0.743 \\
27 & 0.115 & 0.084 & 0.792 \\
28 & 0.696 & 0.579 & 0.738 \\
32 & 0.517 & 0.351 & 0.760 \\
32 & 0.517 & 0.351 & 0.760 \\
\hline
\end{tabular}

$\mathrm{KMO}=0.771 ;$ p M 0.001; Variância explicada $=31.678 \% ; \alpha=.77$

A versão agora utilizada inclui apenas trinta e dois itens, distribuídos pelas três dimensões da escala de avaliação da transferência de conhecimentos da formação para um futuro local de trabalho, respetivamente Conceção da Formação (8 itens), Fatores Individuais (11 itens) e Fatores Organizacionais (13 itens). 


\section{Perceção da transferência de aprendizagens: análise descritiva}

Relativamente às medidas descritivas, os dados que integram o Quadro 5 permitem-nos verificar os resultados da avaliação da perceção da transferência das aprendizagens para um futuro local de trabalho.

Quadro 5

Medidas Descritivas Referentes aos Itens e Escalas de Transferência de Conhecimentos para um Futuro Local de Trabalho

\begin{tabular}{|c|c|c|c|c|c|}
\hline Itens/Escalas & Média & Mediana & $\begin{array}{l}\text { Desvio } \\
\text { padrão }\end{array}$ & $\begin{array}{c}\text { Valor } \\
\text { mínimo }\end{array}$ & $\begin{array}{l}\text { Valor } \\
\text { máximo }\end{array}$ \\
\hline 8 & 3.78 & 4.00 & 0.81 & 1 & 5 \\
\hline 15 & 3.48 & 4.00 & 0.85 & 1 & 5 \\
\hline 16 & 3.82 & 4.00 & 0.78 & 1 & 5 \\
\hline 17 & 3.50 & 4.00 & 0.87 & 1 & 5 \\
\hline 18 & 3.97 & 4.00 & 0.70 & 1 & 5 \\
\hline 19 & 3.82 & 4.00 & 0.78 & 1 & 5 \\
\hline 20 & 3.94 & 4.00 & 0.87 & 1 & 5 \\
\hline 21 & 3.13 & 3.00 & 0.92 & 1 & 5 \\
\hline Conceção da Formação & 3.68 & 3.75 & 0.58 & 1.25 & 5.00 \\
\hline 1 & 3.54 & 4.00 & 0.91 & 1 & 5 \\
\hline 2 & 3.41 & 3.00 & 0.91 & 1 & 5 \\
\hline 3 & 3.93 & 4.00 & 0.98 & 1 & 5 \\
\hline 4 & 4.19 & 4.00 & 0.74 & 1 & 5 \\
\hline 5 & 4.07 & 4.00 & 0.87 & 1 & 5 \\
\hline 22 & 4.21 & 4.00 & 0.70 & 2 & 5 \\
\hline 23 & 4.00 & 4.00 & 0.74 & 1 & 5 \\
\hline 24 & 4.03 & 4.00 & 0.76 & 1 & 5 \\
\hline 29 & 4.01 & 4.00 & 0.68 & 2 & 5 \\
\hline 30 & 3.75 & 4.00 & 0.83 & 1 & 5 \\
\hline 31 & 3.84 & 4.00 & 0.81 & 2 & 5 \\
\hline Fatores Individuais & 3.91 & 3.91 & 0.52 & 2.09 & 4.91 \\
\hline 6 & 3.55 & 4.00 & 0.94 & 1 & 5 \\
\hline 7 & 3.32 & 3.00 & 1.00 & 1 & 5 \\
\hline 9 & 3.64 & 4.00 & 0.86 & 1 & 5 \\
\hline 10 & 3.58 & 4.00 & 0.89 & 1 & 5 \\
\hline 11 & 3.69 & 4.00 & 1.03 & 1 & 5 \\
\hline 12 & 3.95 & 4.00 & 0.82 & 1 & 5 \\
\hline 13 & 3.97 & 4.00 & 0.78 & 1 & 5 \\
\hline 14 & 3.15 & 3.00 & 0.96 & 1 & 5 \\
\hline 25 & 3.91 & 4.00 & 0.72 & 2 & 5 \\
\hline 26 & 3.52 & 4.00 & 0.88 & 1 & 5 \\
\hline 27 & 3.16 & 3.00 & 1.06 & 1 & 5 \\
\hline 28 & 3.68 & 4.00 & 0.84 & 1 & 5 \\
\hline 32 & 3.58 & 4.00 & 0.82 & 1 & 5 \\
\hline Fatores Organizacionais & 3.59 & 3.62 & 0.46 & 1.62 & 4.85 \\
\hline
\end{tabular}


Constatamos que os itens 18, 20, 16 e 19, respetivamente, as atividades e exercícios que os formadores usam, ajudar-me-ão a saber como aplicar num contexto de trabalho aquilo que aprendi, os formadores utilizam muitos exemplos que mostram como posso aplicar num futuro trabalho o que aprendi na formação, acredito que o que é ensinado na formação corresponde às exigências da profissão e considero que os formadores sabem como irei utilizar o que aprendi na formação foram os que mais contribuíram para a perceção de transferência de aprendizagens no âmbito da Conceção da Formação.

Quanto aos Fatores Individuais, verificamos que os itens em que os formandos avaliam de forma mais positiva a perceção de transferência de aprendizagens para um futuro local de trabalho foram os números 22, 4, 5, 24, 29 e 23, concretamente, os itens quanto mais me esforço por aprender, melhor desempenho conseguirei ter no meu trabalho, quando sair da formação espero aplicar no trabalho o que aprendi, acredito que $a$ formação vai ajudar-me a ter um melhor desempenho no meu futuro emprego, quanto mais eu aplicar num futuro trabalho o que aprendi na formação melhor desempenho obterei, estou confiante na minha capacidade de utilizar novos conhecimentos, adquiridos na formação, num futuro trabalho e geralmente a formação ajuda-me a aumentar a minha produtividade.

Verificamos, ainda, que os itens 13, 12, 25, 11, 28 e 9, ou sejam, os itens os meus formadores mostram interesse relativamente ao que aprendi na formação, os meus formadores vêm ter comigo e explicam-me como posso aplicar num futuro trabalho o que aprendi na formação, quando me esforço para melhorar o meu desempenho, acontecem-me coisas boas, os meus formadores vêm ter comigo regularmente para prevenir os problemas que posso ter ao utilizar o que aprendi na formação, os meus colegas de formação estão abertos a mudanças, se isso melhorar o desempenho profissional e os meus colegas encorajam-me a utilizar as competências que aprendi na formação foram aqueles em que os participantes no estudo revelaram maior perceção de transferência da formação ao nível dos Fatores Organizacionais.

Comparando os resultados observados em cada uma das escalas podemos afirmar que os formandos evidenciaram uma perspetiva mais positiva da transferência para um futuro local de trabalho ao nível dos Fatores Individuais, seguida da Conceção da Formação e dos Fatores Organizacionais. Os resultados obtidos vão ao encontro de Cheng e Ho (2001) que indicam que as características individuais explicam o comportamento humano e que as diferenças individuais exercem uma influência considerável na transferência. Globalmente e tendo presente que a escala de avaliação poderia variar entre 1 e 5 pontos, os participantes evidenciaram uma boa perceção de transferência de conhecimentos para um futuro local de trabalho. 


\section{A perceção da transferência de aprendizagem em função de variáveis sociodemográficas}

De acordo com o Quadro 6, podemos constatar a existência de diferenças significativas ao nível da perceção da transferência em função do sexo na escala Fatores Individuais ( $p=0.043$ ), sendo que os elementos do sexo masculino evidenciaram perceção mais positiva da transferência para um futuro local de trabalho que os do sexo feminino.

Quadro 6

Comparação dos Resultados da Escala de Transferência para um Futuro Local de Trabalho em Função do Sexo

\begin{tabular}{cccccc}
\hline $\begin{array}{c}\text { Escalas } \\
\text { Sexo }\end{array}$ & Média ordinal & Média & Mediana & $\mathbf{z}$ & $\mathbf{p}$ \\
\hline $\begin{array}{c}\text { Conceção da Formação } \\
\text { Masculino }\end{array}$ & 106.18 & 3.78 & 3.81 & -1.870 & 0.062 \\
$\quad$ Feminino & 90.33 & 3.63 & 3.75 & & \\
Fatores Individuais & & & & & \\
Masculino & 107.08 & 4.02 & 4.00 & -2.024 & 0.043 \\
Feminino & 89.89 & 3.85 & 3.91 & & \\
Fatores Organizacionais & & & & & \\
Masculino & 103.93 & 3.66 & 3.69 & -1.474 & 0.140 \\
Feminino & 91.42 & 3.56 & 3.62 & & \\
\hline
\end{tabular}

Curiosamente, Wlodkowski (2007) refere um estudo de Hayes e Darkenworld (1990) cujos dados revelam que as mulheres mostram tendencialmente uma atitude mais positiva relativamente à transferência do que os homens. Nos resultados do presente estudo verificamos a situação oposta, que interpretamos através do tipo de ação frequentada, sendo que o sexo masculino integra ações com um caráter mais técnico, onde é possível observar o produto da implementação das aprendizagens nas unidades práticas do curso, enquanto o o sexo feminino frequenta acões bastante direcionadas para conceitos mais teóricos. Embora ambos os cursos tenham componentes práticas, as de maior cariz técnico são frequentadas por homens, fator que pode justificar os resultados obtidos. Como podemos verificar pelos resultados que constituem o Quadro 7, observamos a existência de diferenças estatisticamente significativas nas escalas Conceção da Formação ( $p=0.000$ ) e Fatores Organizacionais ( $p=0.001)$, em função das habilitações escolares. 
Quadro 7

Comparação dos Resultados da Escala de Transferência da Formação para o Local de Trabalho em Função das Habilitações Escolares

\begin{tabular}{|c|c|c|c|c|c|}
\hline $\begin{array}{c}\text { Escalas } \\
\text { Habilitações escolares }\end{array}$ & Média ordinal & Média & Mediana & z & $\mathbf{P}$ \\
\hline \multicolumn{6}{|l|}{ Conceção da formação } \\
\hline $6^{\circ}$ ano & 109.16 & 3.81 & 3.88 & -4.822 & 0.000 \\
\hline $9 \circ$ ano & 68.61 & 3.42 & 3.50 & & \\
\hline \multicolumn{6}{|l|}{ Fatores individuais } \\
\hline 6 ano & 98.31 & 3.94 & 3.91 & -0.990 & 0.322 \\
\hline 9o ano & 89.97 & 3.85 & 3.91 & & \\
\hline \multicolumn{6}{|l|}{ Fatores organizacionais } \\
\hline 60 ano & 104.81 & 3.67 & 3.65 & -3.284 & 0.001 \\
\hline 9 ano & 77.16 & 3.44 & 3.50 & & \\
\hline
\end{tabular}

Comparando os valores médios e medianos somos levados a concluir que os participantes que possuíam o 6a ano tenderam a evidenciar uma perceção mais positiva da transferência para um futuro local de trabalho do que aqueles que possuíam o 9a ano.

Destacamos que os resultados obtidos são coerentes quer ao nível das habilitações literárias iniciais, quer ao nível das habilitações literárias que os formandos esperam obter através da formação que estão a frequentar, pois ambos os resultados estão em consonância. Admitimos que estes dados merecem especial realce, uma vez que diversos autores apontam para resultados opostos. Wlodkowski (2007) refere que os indivíduos com um nível inicial de escolaridade mais elevado tendem a apresentar uma atitude mais positiva do que os indivíduos com um nível inicial de escolaridade mais baixo. Fernandes (2008) aponta o Efeito Mateus como um promotor ou inibidor na aquisição de conhecimentos, sendo que este efeito consiste na conceção de que:

o que mais sabe, quanto mais sabe, mais deseja saber, mais procura saber e mais se the concede saber e o que menos sabe, menos consciente é da sua necessidade de aprender, menos manifesta querer saber e menos ofertas tem para aprender. (p. 90)

Também Caetano (2007) indica que o nível de escolaridade do indivíduo pode influenciar a motivação para a transferência, partindo do pressuposto que um nível mais elevado de escolaridade poderá significar uma maior motivação para transferir. Estamos conscientes que o autor, neste aspeto, não versa diretamente a perceção da transferência, mas a motivação para transferir, o que consideramos estar de alguma forma relacionado com os dados obtidos.

Com efeito, a explicação para o facto de os participantes com o 6응 de escolaridade evidenciarem uma maior perceção de transferência pode estar rela- 
cionada com a obtenção de um nível escolar correspondente à escolaridade mínima obrigatória, significando a formação para estes elementos uma oportunidade para, através de um patamar de escolaridade superior ao que detêm presentemente, integrarem o mercado de trabalho.

A existência de diferenças significativas ao nível da perceção da transferência em função do motivo que levou os sujeitos a frequentarem um curso EFA foi testada aplicando o teste Kruskal-Wallis e os resultados obtidos (cf. Quadro 8) permitem-nos verificar que existem diferenças estatisticamente significativas em todas as escalas.

Quadro 8

Comparação dos Resultados da Escala de Transferência para um Futuro Local de Trabalho em Função do Motivo para Frequentar a Formação

\begin{tabular}{|c|c|c|c|c|c|c|}
\hline Escalas & Motivo & $\begin{array}{l}\text { Média } \\
\text { ordinal }\end{array}$ & Média & Mediana & $x^{2}$ & $\mathrm{p}$ \\
\hline \multicolumn{7}{|c|}{ Conceção da Formação } \\
\hline & Por imposição & 66.99 & 3.40 & 3.50 & \multirow{3}{*}{17.744} & \multirow{3}{*}{0.000} \\
\hline & Por interesse próprio & 101.92 & 3.78 & 3.75 & & \\
\hline & Por sugestão de alguém & 111.28 & 3.88 & 3.88 & & \\
\hline \multicolumn{7}{|c|}{ Fatores Individuais } \\
\hline & Por imposição & 60.29 & 3.58 & 3.54 & \multirow{3}{*}{28.223} & \multirow{3}{*}{0.000} \\
\hline & Por interesse próprio & 108.51 & 4.04 & 4.00 & & \\
\hline & Por sugestão de alguém & 94.04 & 3.97 & 3.91 & & \\
\hline \multicolumn{7}{|c|}{ Fatores Organizacionais } \\
\hline & Por imposição & 72.44 & 3.42 & 3.46 & \multirow{3}{*}{11.207} & \multirow{3}{*}{0.004} \\
\hline & Por interesse próprio & 100.14 & 3.64 & 3.61 & & \\
\hline & Por sugestão de alguém & 107.87 & 3.72 & 3.69 & & \\
\hline
\end{tabular}

Os valores calculados para as medidas de tendência central revelam que os elementos que frequentaram a formação por imposição evidenciaram menor perceção da transferência para um futuro local de trabalho, enquanto os que frequentaram as ações por interesse próprio ou por sugestão de alguém manifestaram uma maior perceção da transferência.

Concluímos que existem evidências estatísticas que revelam que a transferência para um futuro local de trabalho é diferente conforme o motivo que o indivíduo tem para frequentar a formação. Percebemos que o motivo que leva o indivíduo à formação pode ditar o seu comportamento, a aquisição de conhecimentos e, através do Quadro 8, podemos confirmar que o motivo da sua integração numa ação faz toda a diferença. Este resultado era de certa forma esperado, pois de acordo com a revisão da literatura, é determinante para uma transferência positiva o indivíduo tomar decisões por si próprio, com os fatores motivacionais implicados nas suas opções. 
Podemos ainda constatar que existem diferenças significativas ao nível da perceção da transferência em função do grau de satisfação com a formação e em função da confiança do indivíduo na aquisição de trabalho como consequência da formação. Com efeito, procedendo ao estudo da correlação entre as variáveis, utilizando o coeficiente de correlação de Spearman e o respetivo teste de significância, podemos observar, no Quadro 9, que em ambos os casos as correlações são positivas e estatisticamente significativas. Tal pode ser interpretado como evidência de que os indivíduos mais satisfeitos com a formação e mais confiantes na aquisição de trabalho tendem a revelar maior perceção de transferência para um futuro local de trabalho.

Quadro 9

Correlação da Transferência para um Futuro Local de Trabalho com o Grau de Satisfação com a Formação e com a Expetativa Face à Aquisição de Trabalho

\begin{tabular}{ccccc}
\hline \multirow{2}{*}{ Variáveis } & \multicolumn{2}{c}{ Grau de satisfação } & \multicolumn{2}{c}{ Aquisição de trabalho } \\
\cline { 2 - 5 } & rs & $\mathbf{p}$ & rs & $\mathbf{p}$ \\
\hline Conceção da Formação & +0.33 & 0.000 & +0.44 & 0.000 \\
Fatores Individuais & +0.48 & 0.000 & +0.47 & 0.000 \\
Fatores Organizacionais & +0.32 & 0.000 & +0.45 & $\mathbf{0 . 0 0 0}$ \\
\hline
\end{tabular}

Em estudos citados por Caetano (2007), a satisfação com o trabalho surge positivamente associada à transferência, isto é, à aplicação dos conhecimentos. No presente estudo, que incide num contexto formativo, considerámos interessantes os resultados obtidos ao revelarem que, quer os níveis de satisfação com a formação, quer o grau de confiança na integração no mercado de trabalho, estão relacionados com a perceção da transferência.

\section{Conclusões}

No presente estudo procurámos analisar a perceção da transferência das aprendizagens em formandos dos cursos de Educação e Formação de Adultos num Centro de Emprego e Formação Profissional da zona centro de Portugal continental, no decurso do processo de formação, testando de algum modo o modelo e a metodologia propostos por Holton e colaboradores no que se refere ao LTSI.

De forma global, os resultados apontaram para uma perceção positiva de transferência de aprendizagens para as unidades práticas que decorreram ao longo da formação e para um futuro posto de trabalho, evidenciando-se mais elevados na escala Fatores Individuais, seguindo-se a Conceção da Formação e terminando com os Fatores Organizacionais. 
No que diz respeito à perceção da transferência das aprendizagens para um futuro local de trabalho, revelaram-se diferenças significativas em função do sexo e do nível de habilitação, que surgem não convergentes com os resultados de outras investigações (Caetano, 2007, Velada, 2007), sendo que no presente estudo o sexo masculino é aquele que revela maior perceção de transferência, sendo ainda aqueles que detêm menos habilitações escolares que pontuam mais nas escalas de transferência.

Estes dados, que interpretamos em função da natureza dos cursos frequentados e da motivação para transferir, conjugados com a existência de relações significativas entre a perceção da transferência de aprendizagens e o motivo de integração na formação, a satisfação com a formação e a perspetiva de conseguir um emprego devido à formação, chamam a atenção para um conjunto de variáveis que devem constituir matéria de reflexão em futuros estudos, políticas e práticas de formação e de emprego.

Como principais implicações práticas do presente estudo destaca-se a importância das variáveis motivacionais que devem ser objecto de intervenção no quadro da própria formação, no sentido de potenciar a transferência de aprendizagem, bem como o reforço do caráter técnico-prático dos cursos de formação, a ligação à realidade profissional e a intervenção de uma equipa técnica (Conselheiro de Orientação Profissional, Técnicos de Serviço Social e Técnicos de Formação) na planificação e desenvolvimento das ações e acompanhamento dos formandos.

Uma abordagem longitudinal seria, na nossa perspetiva, a forma ideal de encetar um estudo com este público, pois poder-se-ia acompanhar os formandos que conseguissem uma integração num local de trabalho e, dessa forma, avaliar-se a transferência de aprendizagens em diferentes tempos: durante a formação na qualidade de formando, durante o estágio na qualidade de estagiário e durante a atividade laboral na qualidade de colaborador de uma entidade. Com efeito, uma avaliação de resultados finais poderia ter outro impacto a nível de investigação e até mesmo a nível institucional.

\section{Referências bibliográficas}

Baldwin, T., \& Ford, J. (1988) Transfer of training: A review and directions for future research. Personnel Psychology, 41(1), 63-104. doi: 10.1111/j.1744-6570.1988.tb00632.x

Barreira, C. (2009). Os contributos dos Modelos de Kirkpatrick e de Stufflebeam para o desenvolvimento de uma estratégia avaliativa do processo formativo. In H. Ferreira, C. Lima, F. Alves, G. Santos, \& S. Bergamo (Orgs.), X Congresso da Sociedade Portuguesa de Ciências da Educação: Investigar, Avaliar e Descentralizar. Bragança: Instituto Politécnico de Bragança.

Burke, L. A., \& Hutchins, H. M. (2007). Training transfer: An integrative literature review. Human Resource Development Quarterly, 6(3), 263-288. 
Caetano, A. (2007). Avaliação da formação: Estudos em organizações portuguesas. Lisboa: Livros Horizonte.

Canário, R. (2007). Nota de apresentação. Sísifo: Revista sobre Ciências da Educação, 2, 3-4. Cheng, E., \& Ho, D. (2001). A review of transfer of training studies in the past decade. Research Note, 30(1), 102-115. Consultado em http://www.owlnet.rice.edu/ antonvillado/ courses/09a_psyc630001/Cheng\%20\&\%20Ho\%20\%282001\%29\%20PR.pdf

Devos, C., Dumay, X., Bonami, M., Bates, R., \& Holton, E. (2007). The Learning Transfer System Inventory (LTSI) translated into French: Internal structure and predictive validity. International Journal of Training and Development, 11(3), 181-199. doi: 10.1111/j.1468-2419.2007.00280.x

Fernandes, D. (2006). Para uma teoria da avaliação formativa. Revista Portuguesa de Educação, 19(2), 21-50.

Fernandes, D. (2008). Avaliação das aprendizagens: Desafios às teorias, práticas e políticas. Lisboa: Texto Editores.

Holton, E., Bates, R., Seyler, D., \& Carvalho, M. (1997). Toward construct validation of a Transfer Climate Instrument. Human Resource Development Quarterly, 8(2), 95-111.

Holton, E., Bates, R., \& Ruona, W. (2000). Development of a generalized learning transfer system inventory. Human Resource Development Quarterly, 11(4), 333-360. doi: 10.1002/1532-1096

Inácio, M., (2007). Manual do formando: O processo de aprendizagem. Lisboa: Delta Consultores e Perfil em Parceria.

Lázaro, J. (2012). Avaliação da transferência da formação: Um estudo com educadores e professores do ensino básico e secundário (Dissertação de mestrado não publicada). Universidade de Coimbra, Coimbra.

Lopes, L. (2014). Perceção da transferência das aprendizagens em educação e formação de adultos (Dissertação de mestrado não publicada). Universidade de Coimbra, Coimbra.

Maroco, J., \& Garcia-Marques, T. (2006). Qual a fiabilidade do alfa de Cronbach? Questões antigas e soluções modernas? Laboratório de Psicologia, 4(1), 65-90.

Maroco, J. (2007). Análise Estatística com a utilização do SPSS (3a - ed.). Lisboa: Edições Sílabo, Lda.

Miranda. G. L., \& Bahia, S. (2005). Psicologia da educação: Temas de desenvolvimento, aprendizagem e ensino. Lisboa: Relógio D'Água.

Noe, R. A., \& Schmitt, N. (1986). The influence of trainee attitudes on training effectiveness: Test of a model. Personnel Psychology, 39(3), 497-523. doi:10.1111/j.17446570.1986.tb00950.x

Pestana, M. H., \& Gageiro, J. N. (2005). Análise de dados para ciências sociais: A complementaridade do SPSS (4a - ed.). Lisboa: Edições Sílabo, Lda.

Stufflebeam, D., \& Shinkfield, A. (1993). Evaluación sistemática: Guía teórica e prática. Barcelona: Ediciones Paidos Ibérica.

Velada, R. (2007). Avaliação da eficácia da formação profissional: Factores que afectam a transferência da formação para o local de trabalho (Tese de doutoramento não publicada). ISCTE, Lisboa.

Wlodkowski, R. J. (2007). Enhancing adult motivation to learn: A comprehensive guide for teaching all adults (2ª. ed.). Califórnia: Jossey-Bass Inc. Publisher. 